\title{
Detección de hepatitis B oculta en donantes de bancos sangre, Colombia 2008-2009
}

\author{
Mauricio Beltrán¹, Maritza Berrío-Pérez¹, María Isabel Bermúdez¹, Gloria Rey-Benito², \\ Bernardo Camacho ${ }^{3}$, Patricia Forero ${ }^{3}$, Gloria Cristina Molina ${ }^{4}$, Orlando Fals ${ }^{5}$, Isabel Pisciotti ${ }^{5}$, \\ Yulieth Oliveros ${ }^{6}$, Armando Cortés ${ }^{7}$, Fernando De La Hoz \\ 1 Grupo Red Nacional Bancos de Sangre, Instituto Nacional de Salud, Bogotá, D.C., Colombia \\ 2 Grupo de Virología, Instituto Nacional de Salud, Bogotá, D.C., Colombia \\ 3 Hemocentro Distrital, Bogotá, D.C., Colombia \\ ${ }^{4}$ Cruz Roja, Seccional Valle del Cauca, Cali, Colombia \\ 5 Fundación Grupo Estudio Barranquilla, Barranquilla, Colombia \\ ${ }^{6}$ Hospital Rosario Pumarejo de López, Valledupar, Colombia \\ 7 Hospital Universitario del Valle, Cali, Colombia \\ 8 Universidad Nacional de Colombia, Bogotá, D.C., Colombia
}

Introducción. En los bancos de sangre colombianos es obligatoria la tamización para el antígeno de superficie de la hepatitis $B$ en todas las unidades recolectadas, mientras que no lo es para el anticuerpo contra el antígeno central, aunque este último puede ser útil para detectar donantes infectados con el virus de hepatitis $B$.

Objetivo. Determinar la prevalencia de hepatitis B oculta, mediante la aplicación de un perfil serológico completo para el virus de la hepatitis $B$ y pruebas de amplificación de ácidos nucleicos, en donantes de sangre de cuatro ciudades colombianas.

Materiales y métodos. Entre abril de 2008 y octubre de 2009 se llevó a cabo un estudio prospectivo transversal que incluyó 628 muestras de donantes de cuatro bancos de sangre, ubicados en ciudades colombianas que registran distintas prevalencias para infección por el virus de la hepatitis B. Se hizo la tamización serológica completa para el virus y, posteriormente, pruebas de amplificación de ácidos nucleicos a los sueros con anti-HBc total reactivo y título de anti-HBs $\leq 30 \mathrm{mUl} / \mathrm{ml}$.

Resultados. En total, 129 muestras cumplieron con los criterios serológicos establecidos para ser sometidas a pruebas de amplificación de ácidos nucleicos. En ninguna de ellas se obtuvo amplificación de ácidos nucleicos del virus de la hepatitis $B$.

Conclusiones. Éste es el primer estudio en Colombia que busca determinar la presencia de donantes de sangre portadores de hepatitis $B$ oculta. No se documentó ningún caso de infección oculta en el estudio.

Palabras clave: transfusión sanguínea, hepatitis $B$, bancos de sangre. Colombia.

\section{Absence of occult hepatitis B in Colombian blood donors}

Introduction. In Colombian blood banks, screening for the surface antigen of hepatitis B is mandatory in all units collected. Testing of antibody against core antigens is not administered, although this method may be useful to detect donors infected with the hepatitis $B$ virus.

Objective. The prevalence of occult hepatitis B was determined by applying a full-serological profile of hepatitis $B$ virus to blood samples of blood donors.

Materials and methods. Between April 2008 and October 2009, a prospective cross sectional study was conducted using 628 samples from donors to blood banks located in four Colombian cities. Prevalence for hepatitis B had been previously recorded for these cities. Serological screening was performed for the complete virus; then nucleic acid amplification was tested in sera that were anti-HBc reactive and with a titer of anti-HBs $\leq 30 \mathrm{mUl} / \mathrm{ml}$.

Results. Of the 628 samples tested, 129 met the serological criteria established to be tested nucleic acid amplification. None of them demonstrated evidence of nucleic acid amplification of hepatitis $B$ virus.

Conclusions. This is the first study in Colombia to detect the presence of blood donors that may be occult hepatitis B carriers. None was detected.

Key words: Blood transfusion, hepatitis B, blood banks, Colombia. 
La hepatitis B es un problema de salud pública en el mundo. Según la Organización Mundial de la Salud (OMS), se estima que 2.000 millones de personas han sido infectadas con el virus de la hepatitis $B$ y más de 360 millones de personas son portadoras crónicas $(1,2)$; cerca de un millón de personas mueren anualmente por esta enfermedad (3). La infección por el virus de la hepatitis B es la causa infecciosa más importante de enfermedad hepática aguda y crónica en el mundo y una de las principales causas de cirrosis y carcinoma hepatocelular (2).

En América Latina, el número de portadores crónicos del virus de la hepatitis $B$ se estima en 6 millones de individuos, aproximadamente (4). Las zonas endémicas varían según la región geográfica y las características étnicas. Colombia ha sido catalogada como un área medianamente endémica pero, en algunas zonas, la prevalencia de portadores de antígeno de superficie es similar a la encontrada en países muy endémicos.

Existen cinco áreas geográficas definidas como muy endémicas, las cuales se encuentra situadas en la Costa Caribe, el golfo de Urabá, la Costa Pacífica, la base amazónica y la del Catatumbo en límites con Venezuela, en donde más de $70 \%$ de la población ha sido infectada con el virus de la hepatitis $B(5)$. La tasa de incidencia nacional para infección por el virus de la hepatitis $B$ ha oscilado entre 2 y 3 casos por 100.000 habitantes, de 2004 a 2008 (6). En 1992, se introdujo en Colombia el programa de control de infección por el virus de la hepatitis $B$, mediante la vacunación en infantes, cuya cobertura llegó a 93\% en 2007 (5) (Daza L. Informe de evento de hepatitis $\mathrm{B}$, hasta el periodo epidemiológico XIII de 2008. Bogotá: Subdirección de Vigilancia y Control en Salud Pública, Instituto Nacional de Salud; 2009).

La hepatitis B oculta puede definirse como la presencia de ADN en sangre o en tejidos, sin que sea detectable el antígeno de superficie del VHB ( $\mathrm{HBsAg})$, conosin la presenciadeanticuerpos contra el antígeno central o core (anti-HBc) o anticuerpos contra el antígeno de superficie (anti-HBs) (7). La hepatitis B oculta en individuos aparentemente sanos, se encuentra principalmente en cuatro

\footnotetext{
Correspondencia:

Mauricio Beltrán, Grupo Red Nacional Bancos de Sangre, Instituto Nacional de Salud, Calle 26 № 51-20, CAN, Zona 6,

Bogotá, D.C., Colombia

Telefax: (571) 2207700

mbeltrand@ins.gov.co

Recibido: 13/12/10; aceptado:08/09/11
}

condiciones clínicas: individuos recuperados de la infección con presencia de anti-HBs, hepatitis crónica relacionada con mutantes del virus que no son reconocidas por los anticuerpos monoclonales o policlonales de las pruebas serológicas utilizadas, hepatitis crónica en "portadores sanos" con anti$\mathrm{HBc}$ total con la presencia de anti-HBe o sin ella, y portadores sanos sin ningún marcador de infección detectable excepto el ADN del VHB (7).

La prevalencia de hepatitis $B$ oculta varía según la endemia de virus de la hepatitis $B$ en la región; en áreas de baja prevalencia, en no más de $5 \%$ de las unidades de sangre negativas para HBsAg y positivas para anti-HBc, se encuentra ADN del virus de la hepatitis $B$, mientras que en zonas de alta prevalencia (como India y Taiwán), se encuentra ADN viral en 4 a $25 \%$ de las unidades negativas para HBsAg y positivas para anti-HBc (8). En un estudio en Brasil, en donantes de sangre y pacientes positivos para el virus de hepatitis $C$, ambos con presencia de anti-HBc, se halló que la prevalencia de hepatitis $B$ oculta en donantes de sangre fue $6 \%$ y en pacientes infectados con virus de la hepatitis C fue de $24 \%$ (9).

En un estudio en donantes de un banco de sangre en Caracas, Venezuela, se encontró viremia asociada con niveles de anti-HBs inferiores a $30 \mathrm{UI} / \mathrm{L}$, siendo estos potencialmente infecciosos con el virus de hepatitis B (10).

La transfusión sanguínea y el tratamiento con hemocomponentes han sido bien establecidos y son esenciales en la práctica médica. Sin embargo, conllevan el riesgo de transmisión de agentes patógenos, entre ellos el virus de la inmunodeficiencia humana $(\mathrm{VIH})$, el virus de la hepatitis $C$ y el virus de la hepatitis $B$, entre otros posibles eventos adversos.

La seguridad de los componentes sanguíneos depende de múltiples factores, entre ellos, los criterios de selección de donantes, las pruebas serológicas utilizadas para tamizar agentes infecciosos, y demás estrategias o filtros que se establezcan con el fin de disminuir la probabilidad de que individuos con riesgo de infección o unidades de sangre con estándares de calidad inadecuados, lleguen a ser transfundidos (11). Entre estos filtros, las pruebas de tamización con sensibilidad adecuada juegan un papel muy importante en la reducción de la transmisión de agentes patógenos (11).

El riesgo de ser contagiado con una unidad infectada con el virus de la hepatitis B es de $75 \%$ 
$y$, para otros agentes como el virus de la hepatitis $\mathrm{C}$ y el $\mathrm{VIH}$, oscila entre 90 y $100 \%$, y estos virus se consideran los principales agentes de infecciones transmitidas por transfusiones (12).

Con el fin de prevenir la transmisión de agentes infecciosos mediante la transfusión, las técnicas de tamización utilizadas en los bancos de sangre han mejorado considerablemente, gracias al uso de anticuerpos monoclonales, proteínas recombinantes, péptidos sintéticos y novedosos sistemas de detección, con lo que se han obtenido pruebas mucho más sensibles, específicas y confiables (13).

Posteriormente, aparecieron las pruebas de amplificación de ácidos nucleicos y la automatización de las mismas. Las pruebas de amplificación de ácidos nucleicos reducen el periodo de la ventana inmunológica (definido como el tiempo entre la infección y la detección del primer marcador biológico de infección viral) para la hepatitis $B$ en 18 días con la prueba individual de amplificación de ácidos nucleicos, en comparación con las pruebas serológicas para HBsAg que, en promedio, son de 59 días, con una variación entre 37 y 87 días (14). Las pruebas de amplificación de ácidos nucleicos permiten reducir las infecciones en el periodo de ventana por $\mathrm{VIH}$, virus de la hepatitis $\mathrm{B}$ y virus de la hepatitis $C$, e incluso, permiten en algunos casos la detección de pacientes con hepatitis $\mathrm{B}$ oculta. Además, estas pruebas permiten la detección auto-matizada para los tres virus simultáneamente (15).

El riesgo relativo de adquirir una infección transmitida por transfusión en Estados Unidos es baja; siendo éste un país poco endémico, el riesgo se estima en 1:277.000 para el virus de la hepatitis B, comparado con 1:2'135.000 para $\mathrm{VIH}$ y 1 en 1'930.000 para virus de la hepatitis C. Sin embargo, en Europa el riesgo relativo de infecciones transmitidas por transfusión es de 1 en 909.000 a 5'500.000 para $\mathrm{VIH}, 1$ en 200.000 a 4'400.000 para hepatitis C, y 1 entre 72.000 y 1'100.000 para VHB, debido a la gran variación entre zonas de mediana y baja endemia para este último (16).

El anti-HBc se recomienda como marcador en la tamización para la detección de riesgo potencial del virus de la hepatitis $B$ y de estilos de vida, al punto que algunas personas en quienes se había confirmado previamente el $\mathrm{VIH}$ fueron positivas para este marcador (17); además, un porcentaje importante de unidades negativas para HBsAg o positivas para anti-HBc pueden transmitir el virus de la hepatitis $B$, a pesar de que la reactividad para anti-HBc es una causa importante de rechazo y eliminación de unidades en los bancos de sangre (9).

Para el control de la infección por transfusiones, en 1981 se hizo obligatoria en Colombia la tamización para el virus de la hepatitis $B$ mediante la detección del antígeno de superficie, en 1991 fue para $\mathrm{VIH}, \mathrm{y}$ entre 1993 y 1996, se expidieron las normas que regulan las actividades de los bancos de sangre, las cuales incluyeron la detección de estos marcadores y, además, de anticuerpos contra el virus de la hepatitis C, Trypanosoma cruzi y sífilis (18).

El Instituto Nacional de Salud, con base en estudios de prevalencia en donantes, recomendó la aplicación de pruebas para detectar el virus linfotrópico humano (HTLV) y la prueba para el anti-HBc, teniendo en cuenta el papel de este último como marcador de estilo de vida y su ayuda en la reducción del riesgo de infección por el virus de la hepatitis $B$, y que en un estudio preliminar en bancos de sangre se halló una prevalencia de $4,4 \%$, que osciló entre 0 y 12,8 \% (19).

Para el caso del antígeno de superficie de la hepatitis B, en 2009 , los bancos de sangre tamizaron el $100 \%$ de las unidades recolectadas, mientras que, para el anti-HBc, la cobertura de tamización fue $66,7 \%(6)$.

El propósito de este trabajo fue detectar la posible presencia de hepatitis B oculta en donantes de bancos de sangre ubicados en cuatro ciudades con diferente endemia para el virus de la hepatitis $\mathrm{B}$, mediante la aplicación de pruebas serológicas y de amplificación de ácidos nucleicos.

\section{Materiales y métodos}

Se llevó a cabo un estudio descriptivo, prospectivo y transversal, entre mayo de 2008 y octubre de 2009, que incluyó la recolección de muestras de donantes de cuatro bancos de sangre ubicados en Cali, Bogotá, Barranquilla y Valledupar, los cuales captaban, en promedio, 7.000 unidades de sangre al mes.

Los bancos de sangre se seleccionaron considerando su ubicación en zonas de baja, mediana y alta prevalencia de anti-HBc (Bogotá, 2,02 \%; Cali, 3,43 \%; Valledupar, 7,3\%, y Barranquilla, 5,39 \%; datos sin publicar, Red Nacional Bancos de Sangre, 2005). Se tomó como referencia la menor prevalencia de anti-HBc en donantes de sangre, que fue la de Bogotá $(2,0 \%)$ (datos sin publicar, Red Nacional Bancos de Sangre, Instituto Nacional de Salud), teniendo en cuenta que, con baja prevalencia de 
casos (HBsAg negativo y anti-HBc positivo), cerca de $5 \%$ de las pruebas de amplificación de ácidos nucleicos son positivas en donantes con bajos títulos de anti-HBs.

Por tanto, para una prevalencia esperada de este valor $(2,0 \%)$ para anti-HBc, y esperando encontrar una prevalencia de $1,0 \%$ de hepatitis B oculta dentro de la misma muestra, con un nivel de confianza de $95 \%$ se calculó que era necesario recolectar cerca de 530 sueros con sus respectivos plasmas, según cálculos realizados en el programa Epi-Info (versión 6.04); para lograr una mayor representatividad, se adicionó $20 \%$ a la muestra, la cual alcanzó un tamaño de 600 sueros.

Se esperaba obtener este tamaño de muestra en un periodo de 15 meses, estimando que sólo $30 \%$ de los donantes aptos para el estudio (HBsAg negativos y anti-HBc positivos) aceptarían participar. Con el fin de distribuir este valor de forma proporcional, se tuvo en cuenta la captación de unidades de sangre de cada banco de sangre y se obtuvo un tamaño de muestra para cada entidad participante, así: Bogotá, 308; Barranquilla, 41; Valle, 215, y Cesar, 36; el muestreo terminaba una vez se completaran las muestras.

Los donantes de sangre seleccionados para el estudio eran voluntarios que se acercaron a donar por su propia iniciativa y cumplían con los procesos estandarizados de donación de las instituciones participantes, y presentaron resultados de $\mathrm{HBsAg}$ negativo y anti-HBc positivo en la tamización rutinaria de las unidades de sangre en los bancos de sangre.

Estos donantes fueron llamados e informados del estudio mediante entrevista por personal entrenado. Aquellos que decidieron participar libremente, diligenciaron el consentimiento informado y la ficha epidemiológica, y permitieron la toma de muestras adicionales para el estudio. Aquellos donantes que presentaron resultados que sugirieron infección o requirieron asesoría, fueron contactados por los bancos de sangre, para su respectiva canalización en el sistema de salud.

Las encuestas, fichas con datos epidemiológicos y consentimientos informados, fueron revisados y validados en la Coordinación Nacional de la Red de Sangre del Instituto Nacional de Salud, donde, además, se practicaron nuevamente las pruebas serológicas de $\mathrm{HBsAg}$ y anti-HBc, y pruebas como títulos de anti-HBs, anti-HBe, antígeno e, anti$\mathrm{HBc}$ Ig M. Solamente aquellos sueros que fueron simultáneamente reactivos para anti-HBc y no reactivos para HBsAg, y que presentaron títulos de anti-HBs iguales o menores de $30 \mathrm{mUl} / \mathrm{ml}$ con otro marcador serológico o sin él, fueron analizados con pruebas de amplificación de ácidos nucleicos $(10,20)$.

\section{Pruebas serológicas y de amplificación de ácidos nucleicos}

Se obtuvieron muestras de suero y plasma en dos tubos, con el fin de practicar las pruebas serológicas y de amplificación de ácidos nucleicos, respectivamente. Los bancos de sangre utilizaron inmunoensayos para la tamización de la prueba de anti-HBc, así: ELISA tercera generación de Biokit $\AA$, ensayo de micropartículas (MEIA) de Abbott Laboratories y electroquimioluminiscencia de Roche. Los sueros con resultados reactivos a anti-HBc se congelaron y almacenaron a $-80^{\circ} \mathrm{C}$.

En la Coordinación Red Nacional Bancos de Sangre se tamizaron los sueros por inmunoensayo con la técnica de quimioluminiscencia amplificada (Vitros $E C \circledast$, Ortho Clinical Diagnostic, Johnson \& Johnson), para los siguientes marcadores de hepatitis B: HBsAg (antígeno de superficie), anti-HBc (anticuerpo contra el antígeno central), HBc IgM (anticuerpo IgM contra el antígeno central), anti-HBs (anticuerpo contra el antígeno de superficie), HBeAg (antígeno e), anti$\mathrm{HBe}$ (anticuerpo contra antígeno e).

Las muestras que fueron no reactivas al anti-HBc en el INS, se analizaron nuevamente por el inmunoensayo de quimioluminiscencia (Architect $\AA$, Abbott Laboratories) en un tercer laboratorio. Aquellas muestras que resultaron doblemente reactivas al anti-HBc y cumplían los criterios de inclusión, se tamizaron con pruebas de amplificación de ácidos nucleicos para detectar ADN viral, con PCR Cobas Taqscreen MPX Test $\AA$, Cobas 201 System (Roche), que tiene un límite de detección de 3,8 UI/ $\mathrm{ml}$ o 19 copias/UI. En las pruebas de amplificación de ácidos nucleicos se usó una mezcla de seis muestras que cumplieran los criterios definidos previamente (21).

\section{Análisis de resultados}

Los resultados de las variables y de las pruebas serológicas se analizaron con estadística descriptiva, mediante proporciones y porcentajes, utilizando Exce|® y Epi-Info versión 6.04.

\section{Resultados}

En el periodo de estudio, los bancos captaron 127.808 donantes; 2.923 fueron reactivos para anti-HBc y 628 aceptaron participar en el estudio, 
los cuales procedían de Bogotá (313), Barranquilla (50), Cali (208) y Valledupar (57). Se presentan aquí los datos de 129 (20,54\%) muestras que fueron reactivas a anti-HBc y negativas a $\mathrm{HBsAg}$, con títulos menores de $30 \mathrm{mUl} / \mathrm{ml}$ de anti-HBs, y que fueron analizadas por pruebas de amplificación de ácidos nucleicos para el ADN del VHB. La distribución serológica de las muestras restantes se hizo acorde con los estadios descritos por la Organización Mundial de la Salud (OMS) y hacen parte de un documento en elaboración.

De las 129 muestras de donantes, se halló que la edad promedio fue de 43 años con una distribución modal de 48 años. La distribución de donantes fue $47(36,4 \%)$ captados en Valle del Cauca, 47 (36,4 \%) en Bogotá, 21 (16,2\%) en Barranquilla y 14 (10,8 \%) en Valledupar (cuadro 1).

De las 129 muestras que fueron procesadas por pruebas de amplificación de ácidos nucleicos, 86
$(66,7 \%)$ fueron negativas para anti-HBs (títulos inferiores a $10 \mathrm{mUl} / \mathrm{ml})$; de éstas, 65/86 (75,58 \%) presentaron como único marcador serológico antiHBc total, $19(22,09 \%)$ presentaron reactividad para anti-HBc total y anti-HBe, y dos muestras tenían presencia de anti-HBc lgM, de las cuales, una presentó, además, reacción a anti-HBe (cuadro 2). Por otro lado, 43/129 muestras fueron positivas para anti-HBs con títulos entre 10 y $30 \mathrm{mUl} / \mathrm{ml}$; de éstas, $28(65,12 \%)$ presentaron, además, reacción a anti$\mathrm{HBc}$ total y 15 (34,88\%) presentaron reactividad a anti-HBc total y anti-HBe (cuadro 3).

No se obtuvo amplificación de ácidos nucleicos del virus de la hepatitis $B$ en ninguna de las 129 muestras analizadas.

\section{Discusión}

Según la clasificación de la OMS, en Suramérica las prevalencias para infección por el virus de

Cuadro 1. Estadios de la infección por el virus de hepatitis B, por ciudad

\begin{tabular}{|c|c|c|c|c|c|c|c|c|c|c|}
\hline \multirow{3}{*}{$\begin{array}{l}\text { Interpretación/ } \\
\text { serológico }\end{array}$} & \multirow{2}{*}{\multicolumn{2}{|c|}{$\begin{array}{l}\text { Barranquilla, } \\
\text { total captado } \\
(n=50)\end{array}$}} & \multirow{2}{*}{\multicolumn{2}{|c|}{$\begin{array}{l}\text { el virus de hep } \\
\text { Valledupar, } \\
\text { total captado } \\
\quad(n=57\end{array}$}} & tis $B$, & or ciudac & \multirow{2}{*}{\multicolumn{2}{|c|}{$\begin{array}{l}\text { Bogotá, } \\
\text { total captado } \\
(n=313)\end{array}$}} & \multirow{2}{*}{\multicolumn{2}{|c|}{$\begin{array}{c}\text { Total } \\
\text { pruebas - NAT }\end{array}$}} \\
\hline & & & & & \multicolumn{2}{|c|}{$\begin{array}{l}\text { Cali, } \\
\text { total captado } \\
(n=208)\end{array}$} & & & & \\
\hline & $\mathbf{n}$ & $\%$ & $\mathbf{n}$ & $\%$ & $\mathbf{n}$ & $\%$ & $\mathbf{n}$ & $\%$ & $\mathbf{n}$ & $\%$ \\
\hline $\begin{array}{l}\text { Hepatitis B aguda, estado de } \\
\text { portador persistente }\end{array}$ & 1 & 2,00 & - & - & - & - & - & - & 1 & 0,78 \\
\hline $\begin{array}{l}\text { Hepatitis B crónica, estado de } \\
\text { portador persistente }\end{array}$ & & - & & - & & - & 1 & 0,32 & 1 & 0,78 \\
\hline $\begin{array}{l}\text { Convalecencia - infección en } \\
\text { pasado reciente }\end{array}$ & 9 & 18,00 & 3 & 5,26 & 11 & 5,29 & 11 & 3,51 & 34 & 26,36 \\
\hline Recuperado pérdida anti-HBsAg & 7 & 14,00 & 8 & 14,04 & 27 & 12,98 & 23 & 7,35 & 28 & 21,71 \\
\hline $\begin{array}{l}\text { Recuperado -infección en } \\
\text { pasado reciente }\end{array}$ & $\begin{array}{r}4 \\
21\end{array}$ & $\begin{array}{r}8,00 \\
42,00\end{array}$ & $\begin{array}{r}3 \\
14\end{array}$ & $\begin{array}{r}5,26 \\
24,56\end{array}$ & $\begin{array}{r}9 \\
47\end{array}$ & $\begin{array}{r}4,33 \\
22,60\end{array}$ & $\begin{array}{l}12 \\
47\end{array}$ & $\begin{array}{c}3,83 \\
15,02\end{array}$ & $\begin{array}{r}28 \\
129\end{array}$ & $\begin{array}{r}21,71 \\
100,00\end{array}$ \\
\hline
\end{tabular}

NAT: pruebas de amplificación de ácidos nucleicos

Cuadro 2. Muestras analizadas por pruebas de amplificación de ácidos nucleicos, según perfiles serológicos y estadios de la infección por el virus de hepatitis B

\begin{tabular}{|c|c|c|c|c|c|c|c|c|}
\hline Interpretación/perfil serológico & HBsAg & Anti-HBc & Anti-HBs & HBeAg & Anti-HBe & $\mathrm{HBc} \lg M$ & $\mathrm{n}$ & $\%$ \\
\hline $\begin{array}{l}\text { Hepatitis B aguda, estado de } \\
\text { portador persistente }\end{array}$ & $(-)$ & $(+)$ & $(-)$ & $(-)$ & $(-)$ & $(+)$ & 1 & 0,78 \\
\hline $\begin{array}{l}\text { Hepatitis B crónica, estado de } \\
\text { portador persistente }\end{array}$ & $(-)$ & $(+)$ & $(-)$ & $(-)$ & $(+)$ & $(+)$ & 1 & 0,78 \\
\hline $\begin{array}{l}\text { Convalecencia - infección en } \\
\text { pasado reciente }\end{array}$ & $(-)$ & $(+)$ & $(-/+)$ & $(-)$ & $(+)$ & $(-)$ & 34 & 26,4 \\
\hline Recuperado pérdida anti-HBsAg & $(-)$ & $(+)$ & $(-)$ & $(-)$ & $(-)$ & $(-)$ & 65 & 50,4 \\
\hline \multirow{2}{*}{$\begin{array}{l}\text { Recuperado -infección en } \\
\text { pasado reciente }\end{array}$} & $(-)$ & $(+)$ & $(+)$ & $(-)$ & $(-)$ & $(-)$ & 28 & 21,7 \\
\hline & Total & & & & & & 129 & 100 \\
\hline
\end{tabular}


Cuadro 3. Correlación de los títulos de anticuerpos contra el antígeno de superficie de la hepatitis B y edad del donante

\begin{tabular}{lrrrrrrrr}
\hline & \multicolumn{2}{c}{$\mathbf{1 8 - 3 0}$} & \multicolumn{2}{c}{$\mathbf{3 1 - 4 5}$} & & $\mathbf{4 6 - 6 5}$ & \multicolumn{2}{c}{ Total } \\
\cline { 2 - 9 } Títulos de anti-HBs $(\mathbf{m U l} / \mathbf{m l})$ & $\mathbf{n}$ & $\%$ & $\mathbf{n}$ & \% & $\mathbf{n}$ & \% & $\mathbf{n}$ & \% \\
\hline $0-10$ & 17 & 13,2 & 29 & 22,5 & 40 & 31,0 & 86 & 66,7 \\
$10,1-30$ & 7 & 5,4 & 13 & 10,1 & 23 & 17,8 & 43 & 33,3 \\
Total & 24 & 18,6 & 42 & 32,6 & 63 & 48,8 & 129 & 100 \\
\hline
\end{tabular}

la hepatitis B son diversas. Entre las zonas geográficas de alta prevalencia, tenemos la región amazónica, cuya población presenta prevalencias para el HBsAg que varían entre 3,4 y $54 \%$, en países como Brasil, Colombia, Ecuador, Perú y Venezuela $(22,23)$.

Colombia ha sido categorizada como un país de endemia intermedia para el virus de la hepatitis B, que varía según la región geográfica estudiada. Para 2009, según las estadísticas manejadas por el Instituto Nacional de Salud, se hallaron incidencias de 3,35 por 100.000 habitantes en Cesar; 2,9 en Atlántico; 3,7 en Bogotá; 1,6 en Valle del Cauca, y, en departamentos de la Amazonia colombiana, 42,4 en Guainía, 28,4 en Guaviare y 4,87 en Vaupés. Cada año se presentan, en promedio, 2 y 3 casos por 100.000 habitantes de infección por VHB en la población general (Sabogal A. Informe del evento hepatitis $\mathrm{B}$, hasta el periodo epidemiológico XIII de 2009. Bogotá: Subdirección de Vigilancia y Control en Salud Pública, Instituto Nacional de Salud, 2009).

Sin embargo, considerando que solamente $25 \%$ de los casos de hepatitis $B$ son sintomáticos y que estudios previos han estimado cerca de $80 \%$ de subregistro (24), se esperaría tener en la notificación nacional anual, una tasa de 57,42 por 100.000 habitantes. Considerando los casos reportados para 2009 , este dato es acorde con la categorización de Colombia como de endemia intermedia para el virus de la hepatitis B. Además, con los datos de donantes de sangre de 2009, en los que la reacción para HBsAg fue de $0,23 \%$ en promedio nacional, (cerca de $40 \%$ confirmada como positiva para HBsAg), se puede estimar que por cada 100.000 donaciones se presentarían cerca de 88 casos (Red Nacional Bancos de Sangre, Instituto Nacional de Salud).

Durante la fase de infección aguda por el virus de la hepatitis $B$, aparecen diferentes antígenos $y$ anticuerpos, y algunos permanecen en estados crónicos de la infección; su detección permite ubicar al individuo en patrones serológicos definidos. Sin embargo, existen patrones atípicos que dificultan la interpretación y la asignación del individuo en un estadio específico; distintos factores, como títulos bajos de anticuerpos o fenómenos relacionados con mutantes de escape o variantes del virus de la hepatitis $\mathrm{B}$, son responsables de ello.

Los individuos positivos para anti-HBc y con hepatitis B oculta, pueden dividirse en dos grupos, los que presentan anti-HBs y los que no; la tasa de los negativos para el anti-HBs es mayor (25).

Varios marcadores serológicos del virus de la hepatitis B son de ayuda para la clasificación de las muestras con ADN de dicho virus. En las zonas de baja prevalencia, la detección de anti-HBc es de gran ayuda para la confirmación del ADN del VHB. En otras áreas, como la región de Asia oriental y el África subsahariana, donde la prevalencia de anti$\mathrm{HBc}$ supera el $50 \%$ de la población de donantes, un resultado positivo para anti-HBc no proporciona un complemento confiable para decidir entre un verdadero y un falso resultado positivo de ADN del virus de la hepatitis $B$. Sin embargo, la presencia de anti-HBc, unida a la de anti-HBs, indica una infección resuelta con persistencia del ADN del VHB (26). En varios estudios se ha informado viremia (hepatitis $B$ oculta) en individuos con títulos de anti-HBs inferiores a $30 \mathrm{mUl} / \mathrm{ml}$ (10).

Al analizar las 129 muestras evaluadas por pruebas de amplificación de ácidos nucleicos, según los perfiles serológicos para el virus de la hepatitis $B$, se halló que $34(26,3 \%)$ muestras presentaron reactividad para anti-HBc y anti-HBe, con títulos de anti-HBs inferiores a $30 \mathrm{mUl} / \mathrm{ml}$, lo que indica un posible estado de convalecencia (infección en el pasado reciente). Algunos investigadores consideran que la presencia de $\mathrm{HBeAg}$, o más frecuentemente anti-HBe, puede confirmar el valor de anti-HBc en la detección de exposición (27). La hepatitis B oculta puede observarse en pacientes con infección crónica por virus de la hepatitis $B$ con reactividad para el anti-HBc; esto sucede por el declive del HBsAg a un nivel indetectable, algunas veces asociado a la aparición del anti-HBs. Este patrón ocurre entre 0,7 y 1,3\% por año y está asociado con personas de mayor edad (adultos mayores) y la presencia del anti-HBe (26). 
De otro lado, el hallazgo de 65 (50,3\%) donantes que solamente presentaron reactividad para el anti-HBc, podría explicarse porque en algunos pacientes existe un período de ventana de varias semanas 0 , inclusive, meses de duración, en el cual no puede detectarse ni HBsAg ni anti-HBs; de igual forma sucede en personas recuperadas de la infección por el virus de la hepatitis $B$, pero con pérdida detectable del anti-HBs, lo que origina un resultado negativo para el anti-HBs por el paso del tiempo, considerando que 33/65 (50,8\%) donantes tenían más de 46 años de edad. Es de resaltar que la posibilidad de un resultado falso positivo a anti-HBc, por baja especificidad de las pruebas de laboratorio, se reduce, dado que la reactividad de estas muestras corresponde a un doble análisis con técnicas enzimáticas con diferentes principios de detección (28).

De las muestras, 28/129 (21,70 \%) presentaron reactividad para anti-HBc y anti-HBs, pero con títulos inferiores a $30 \mathrm{Ul} / \mathrm{ml}$, lo que muestra la exposición de estos individuos al virus de la hepatitis $B$ en algún periodo de su vida y memoria inmunológica para el virus de la hepatitis $B, y$ que podrían ser evaluados frente a su inmunidad serológica, considerando que se han informado casos de hepatitis B oculta en individuos con títulos inferiores a $30 \mathrm{UI} / \mathrm{L}$ (10).

La diferencia en los hallazgos de unidades de sangre HBsAg no reactivas y anti-HBc reactivas, que son reactivas para ADN viral, puede basarse en varios factores como el grado de endemia de la zona geográfica para la infección con el VHB. En India, considerado un país endémico para la infección por el virus de la hepatitis $B$, en un estudio llevado a cabo en 2007 , durante un periodo de dos años, con un tamaño de 1.027 muestras y reacción de $18,3 \%$ a anti-HBc, se hallaron $21,3 \%$ muestras positivas para ADN (en muestras HBsAg no reactivas y anti-HBc reactivas) (20). Por otro lado, en Canadá, considerado como un país poco endémico para el virus de la hepatitis B, en 2007 se hizo un estudio durante 18 meses en donantes de sangre con doble reacción para anti-HBc $(1,13$ $\%)$, y se hallaron $0,52 \%(n=29)$ positivos para ADN del virus de la hepatitis $B$, en muestras que eran no reactivas para HBsAg (29).

Otro factor que influye en la detección de ADN viral en unidades de sangre $\mathrm{HBsAg}$ no reactivas y anti- $\mathrm{HBc}$ reactivas, es la posible falsa reacción por dilución de la muestra, lo cual está sustentado en algunos estudios que demuestran mayor detección de muestras positivas para ADN del virus de la hepatitis $B$, cuando el análisis se hace en muestras individuales (87,9\%), en comparación con los hechos en grupos de cuatro muestras (67,9\%) (14). Esto puede explicarse considerando que el grupo puede tener algún impacto sobre la eficacia de la detección de virus de la hepatitis $B$ en muestras con cargas virales bajas, en los que esa carga viral inicial, al mezclarse con otras muestras, se diluye proporcionalmente al número de muestras mezcladas en el grupo.

Asimismo, se sabe que en la hepatitis B oculta la carga viral es muy baja, razón por la cual la sensibilidad de las pruebas de detección es crítica (26). Estas situaciones podrían explicar porque, en en el presente estudio, dos muestras con reacción a HBc total y anti-HBc lgM, una de ellas además a anti-HBe, que sugieren perfil serológico de infección aguda y una probable hepatitis B crónica (portador persistente), respectivamente, no fueron positivas en las pruebas de amplificación de ácidos nucleicos y están pendientes para hacerles una prueba molecular individual. Por otro lado, en un reciente estudio de Arroyave, et al., (Antioquia, Colombia) en 144 muestras no reactivas para HBsAg y reactivas para anti-HBc mediante una PCR in house, en los resultados preliminares se encontró $0,69 \%$ de positivos para ADN del virus de la hepatitis $B$ en el análisis individual de muestras (Arroyave JC, Uribe M, Pineda V, Olarte JC, Loureiro CL, Pujol F, et al. Infección oculta por el virus de la hepatitis $B$ en una población de donantes de sangre en Colombia. Medicina, VI Congreso Colombiano, XIII Congreso Iberoamericano, V Simposio Andino de Bancos de Sangre y Medicina Transfusional, III Simposio Colombiano de Bancos de Tejidos, Bogotá, 2010. Medicina Transfusional al Día, 2010;9:2:69).

Otra posible causa para explicar la posibilidad de falsos negativos en las pruebas de amplificación de ácidos nucleicos, se debe a que para el virus de la hepatitis $B$ se han descrito ocho genotipos $(A-H)$; en Colombia y Venezuela, hay una alta prevalencia del virus de la hepatitis $B$ de genotipo $F$, mientras que en Brasil es menos frecuente (30). Estos genotipos presentan una divergencia mínima de $8 \%$ entre las secuencias del genoma completo; los genotipos $\mathrm{F}$ y $\mathrm{H}$ son los más divergentes y son autóctonos de América $(30,31)$. El HBsAg contiene un epítopo principal para la inducción de respuesta inmunitaria humoral, que se localiza en una región conocida como "determinante a", entre los aminoácidos 99 y 169, y están implicados en 
la unión de anticuerpos contra el HBsAg. Se han reportado cambios en los aminoácidos de esta región, que generan cepas mutantes que pueden escapar a la respuesta inmunitaria inducida por las vacunas y, de igual manera, a la detección del HBsAg en las pruebas convencionales de tamización, lo que lleva a resultados no reactivos o débilmente reactivos $(25,32)$. Esta situación del HBsAg mutante se ha reportado como probable en pacientes con perfil serológico inusual del virus de la hepatitis $\mathrm{B}$, anti-HBc aislado, $\mathrm{HBeAg}$ reactivo, anti-HBs positivo o ADN positivo del virus de la hepatitis B, pero en ausencia de HBsAg (33).

Además, se encuentran reportes que muestran una relación de coinfección con el virus de hepatitis $C$ en pacientes que resultaron reactivos para anti$\mathrm{HBc}$ e, incluso, se detectó $5 \%$ de aislamientos de anti-HBc que presentaban coinfección con virus de la hepatitis C y VIH (31). Esta situación es relevante ya que se ha reportado que, en casos de coinfección con el virus de la hepatitis $\mathrm{C}$, el tiempo promedio de detección serológico del HBsAg puede extenderse de 59 días, cuando se presenta infección solamente por el virus de la hepatitis $\mathrm{B}$, a 97 días, en los casos de coinfección del virus de la hepatitis B y C (25); esto sucede por desajustes en la replicación del virus de la hepatitis $B$ y reducción de la síntesis de antígeno de superficie.

Finalmente, debe considerarse el sesgo de selección que conlleva el que no todos los donantes acepten participar en el estudio, lo cual podría hacer que se seleccionen aquellos de menor riesgo de infección por el virus de la hepatitis B. Como se mencionó previamente, son varias las causas que muestran diferencia de resultados del ADN viral en unidades de sangre $\mathrm{HBs} A g$ no reactivas y anti-HBc reactivas.

En este estudio, ninguna de las muestras que se sometieron a pruebas de amplificación de ácidos nucleicos fue positiva, a pesar de que los cuatro bancos de sangre participantes detectaron $2.923(2,29 \%)$ muestras reactivas para anti-HBc mediante la tamización de 127.808 donantes durante el periodo de estudio y que el cálculo de muestra establecido permitía este hallazgo; esto, además de que recientemente un banco de sangre ubicado en Bogotá reportó el hallazgo de tres muestras positivas en pruebas de amplificación de ácidos nucleicos de 125.118 muestras de donantes tamizadas, de las cuales dos fueron reactivas solamente para anti-HBc y una no presentó ningún marcador serológico reactivo y correspondió a una infección aguda en ventana serológica, respalda los argumentos de la falta de detección en el estudio y sugiere, entonces, que la prevalencia de hepatitis B oculta puede estar alrededor de 3/125.000 donaciones (Mora C, Camacho BA. Experiencia con el tamizaje de pruebas NAT en el Hemocentro Distrital de Bogotá. VI Congreso Colombiano, XIII Congreso Iberoamericano, V Simposio Andino de Bancos de Sangre y Medicina Transfusional, III Simposio Colombiano de Bancos de Tejidos; 2010; Bogotá. Medicina Transfusional al Día; 2010.69).

Actualmente, en Colombia, $36 \%$ de las unidades de sangre recolectadas no están siendo tamizadas para anti-HBc y sólo $8 \%$ se analizan para la detección de ácidos nucleicos, en grupos de seis unidades por prueba. Si consideramos los datos del estudio de Arroyabe,basados en muestras individuales, se estimarían cerca de 55 casos de hepatitis B oculta al año, de los cuales 20 casos podrían haberse presentado durante el periodo de estudio, tomando como referencia los datos descritos de bancos de sangre en pruebas de amplificación de ácidos nucleicos practicadas en grupos, se esperarían 16 casos al año y, de éstos, al menos, cinco casos podrían corresponder a hepatitis B oculta en ventana inmunológica.

Al analizar los datos anteriores, serían varias las consideraciones que respaldarían hacer la prueba anti-HBc en todas las unidades de sangre en Colombia. Cerca de 20 de los casos de hepatitis B oculta pueden presentarse en ausencia de todos los marcadores serológicos del virus, pero con presencia de su material genético; es decir, en período de ventana inmunológica, $50 \%$ son positivos para anti-HBc, con presencia de anti-HBs o sin ella, y $35 \%$ son positivos para anti-HBs, con presencia de anti-HBc o sin ella (25). Varios autores han hallado en donantes de sangre negativos para $\mathrm{HBsAg}$ y reactivo para anti-HBc, entre 5 y $20 \%$ de casos con ADN positivo (10); la coinfección con otros agentes infecciosos, como el virus de la hepatitis $C$, puede reducir la carga viral o antigénica de HBsAg; igualmente, la existencia de mutantes del virus de la hepatitis B genera cepas que pueden escapar a la detección del HBsAg $(25,34)$.

En resumen, el presente estudio revela que la reacción para anti-HBc permite identificar con razonable certeza a individuos que han estado expuestos al virus de la hepatitis $B$; no son muchos los falsos positivos y cerca de $20 \%$ de estos individuos tienen riesgo de transmisión de la hepatitis $\mathrm{B}$, de acuerdo con la clasificación de los estados de la infección 
según los resultados serológicos. A pesar de las limitaciones de este estudio en relación con la práctica de grupos de muestras para la prueba de ADN viral, los datos aquí presentados permiten estimar que entre 8 y 20 casos de hepatitis B oculta al año podrían ser transmitidos por transfusión, los cuales podrían reducirse en cerca de $70 \%$ con la implementación de anti-HBc en la tamización de todas las unidades de sangre.

\section{Agradecimientos}

Al personal de los diferentes bancos de sangre participantes en el estudio: Hemocentro Distrital Bogotá, Cruz Roja Seccional Valle del Cauca, Fundación Grupo Estudio Barranquilla, Hospital Rosario Pumarejo de López, Hospital Universitario del Valle, por su apoyo. A Productos Roche, por su apoyo para la realización de las pruebas de amplificación de ácidos nucleicos. Así mismo, se agradece la financiación a la investigación, aportada por Colciencias.

\section{Conflicto de intereses}

Los autores declaran no tener de manera directa o indirecta, ningún tipo de conflicto de intereses financieros, académicos o laborales que puedan poner en peligro la validez de este estudio.

\section{Financiación}

Este trabajo se realizó con el apoyo financiero del Departamento Administrativo de Ciencia, Tecnología e Innovación-Colciencias, proyecto 2104-343-19190, el Instituto Nacional de Salud y los bancos de sangre incluidos en el proyecto Hemocentro Distrital, Hospital Rosario Pumarejo, Fundación Grupo Estudio, Cruz roja seccional Valle del Cauca. Hospital Universitario Del Valle.

\section{Referencias}

1. Valsamakis A. Molecular testing in the diagnosis and management of chronic hepatitis B. Clin Microbiol Rev. 2007;20:426-39.

2. Lavanchy D. Worldwide epidemiology of HBV infection, disease burden, and vaccine prevention. J Clin Virol. 2005;34(Suppl.1):S1-3.

3. Ferir G, Kaptein S, Neyts J, De Clercq E. Antiviral treatment of chronic hepatitis B virus infections: The past, the present and the future. Rev Med Virol. 2008;18:19-34.

4. Shepard CW, Simard EP, Finelli L, Fiore AE, Bell BP. Hepatitis $B$ virus infection: Epidemiology and vaccination. Epidemiol Rev. 2006;28:112-25.

5. De la Hoz F, Pérez L, de Neira M, Hall AJ. Eight years of hepatitis $B$ vaccination in Colombia with a recombinant vaccine: Factors influencing hepatitis $B$ virus infection and effectiveness. Int J Infect Dis. 2008;12:183-9.
6. Beltrán M, Arbeláez MP, Donando J, Jaramillo S, De la Hoz F, Estrada C, et al. Seroprevalencia de infección por virus de la hepatitis $B$ y por virus de la inmunodeficiencia humana en una población de pacientes con múltiples transfusiones en cuatro hospitales, Colombia, Sur América. Biomédica. 2009;29:232-43.

7. Allain JP. Occult hepatitis B virus infection: Implications in transfusion. Vox Sang. 2004;86:83-91.

8. Liu CJ, Chen DS, Chen PJ. Epidemiology of HBV infection in Asian blood donors: Emphasis on occult HBV infection and the role of NAT. J Clin Virol. 2006;36(Suppl.1):S33-44.

9. Pereira JS, Goncales NS, Silva C, Lazarini MS, Pavan $\mathrm{MH}$, Fais VC, et al. HBV vaccination of HCV-infected patients with occult HBV infection and anti-HBc-positive blood donors. Braz J Med Biol Res. 2006;39:525-31.

10. Gutiérrez C, León G, Loureiro CL, Uzcátegui N, Liprandi F, Pujol FH. Hepatitis B virus DNA in blood samples positive for antibodies to core antigen and negative for surface antigen. Clin Diagn Lab Immunol. 1999;6:768-70.

11. Bhatti FA, Ullah Z, Salamat N, Ayub M, Ghani E. Antihepatits $B$ core antigen testing, viral markers, and occult hepatitis B virus infection in Pakistani blood donors: Implications for transfusion practice. Transfusion. 2007;47:74-9.

12. Centers for Disease Control and Prevention. Provisional public health service inter-agency recommendations for screening donated blood and plasma antibody to virus causing acquired inmunodeficiency syndrome. MMWR Morb Mortal Wkly Rep. 1985;34:1-5.

13. Beltrán M, Ayala, M. Evaluación externa de los resultados serológicos en los bancos de sangre de Colombia. Rev Panam Salud Pública. 2003;13:138-43.

14. Comanor L, Holland P. Hepatitis B virus blood screening: Unfinished agendas. Vox Sang. 2006;91:1-12.

15. Yang MH, Li L, Hung YS, Hung CS, Allain JP, Lin KS, et al. The efficacy of individual-donation and minipool testing to detect low-level hepatitis B virus DNA in Taiwan. Transfusion. 2009;50:65-74.

16. Bihl F, Castelli D, Marincola F, Dodd RY, Brander C. Transfusion-transmitted infections. J Transl Med. 2007;5:25.

17. Ramia S, Mokhbat J, Ramlawi F, El-Zaatari M. Occult hepatitis B virus infection in HIV-infected Lebanese patients with isolated antibodies to hepatitis B core antigen. Int J STD AIDS. 2008;19:197-9.

18. Ministerio de Salud. Decreto 1571 de 1993 "Sangre segura para todos”. Bogotá: Ministerio de Salud; 1993.

19. Beltrán M. Prevalencia de anticuerpos contra el antígeno central de hepatitis b (anti-HBc) en donantes de 11 bancos seccionales de sangre, enero a agosto de 1997. Inf Quinc Nac Epidemiol Nac. 1997;2:249-351.

20. Bhattacharya P, Chandra PK, Datta S, Banerjee A, Chakraborty S, Rajendran K, et al. Significant increase in HBV, HCV, HIV and syphilis infections among blood donors in West Bengal, Eastern India 2004-2005: Exploratory screening reveals high frequency of occult HBV infection. World J Gastroenterol. 2007;13:3730-3.

21. Ohhashi Y, Pai A, Halait H, Ziermann R. Analytical and clinical performance evaluation of the cobas TaqScreen 
MPX test for use on the cobas s 201 system. J Virol Methods.165:246-53.

22. Monsalve-Castillo F, Echevarría JM, Atencio R, Suárez A, Estávez J, Costa-León L, et al. High prevalence of hepatitis B infection in Amerindians in Japreira, Zulia State, Venezuela. Cad Saude Publica. 2008;24:1183-6.

23. EI Khouri M, Duarte LS, Ribeiro RB, da Silva LF, Camargo LM, dos Santos VA, et al. Seroprevalence of hepatitis B virus and hepatitis $C$ virus in Monte Negro in the Brazilian western Amazon region. Clinics. 2005;60:29-36.

24. De la Hoz F. Comportamiento de la notificación por SIVIGILA para hepatitis B, 1997-2001. Inf Quinc Epidemiol Nac. 2001;6:253-68

25. Hollinger FB, Sood G. Occult hepatitis B virus infection: A covert operation. J Viral Hepat. 2010;17:1-15.

26. Allain JP, Candotti D. Diagnostic algorithm for HBV safe transfusion. Blood Transfus. 2009;7:174-82.

27. Hollinger FB. Hepatitis B virus infection and transfusion medicine: Science and the occult. Transfusion. 2008;48:1001-26.

28. Alegre D, Moreno J, Quiroga F. Infección aguda por el VHB acute infection by hepatitis B virus. An Sist Sanit Navar. 2004;27(Suppl.2):17-25.

29. O'Brien SF, Fearon MA, Yi QL, Fan W, Scalia V, Muntz IR, et al. Hepatitis $B$ virus DNA-positive, hepatitis $B$ surface antigen-negative blood donations intercepted by anti-hepatitis B core antigen testing: The Canadian Blood Services experience. Transfusion. 2007;47:1809-15.

30. Devesa M, Loureiro CL, Rivas Y, Monsalve F, Cardona $\mathbf{N}$, Duarte MC, et al. Subgenotype diversity of hepatitis B virus American genotype $\mathrm{F}$ in Amerindians from Venezuela and the general population of Colombia. J Med Virol. 2008;80:20-6.

31. Colomina-Rodríguez J, González-García D, BurgosTeruel A, Fernández-Lorenz N, Guerrero-Espejo A. Significado de la reactividad aislada anti-HBc como único marcador de infección de la hepatitis B. Enferm Infecc Microbiol Clin. 2005;23:80-5.

32. Ruiz-Tachiquin ME, Valdez-Salazar HA, Juárez-Barreto V, Dehesa-Violante M, Torres J, Munoz-Hernández O, et al. Molecular analysis of hepatitis B virus "a" determinant in asymptomatic and symptomatic Mexican carriers. Virol J. $2007 ; 4: 6$

33. La'ulu SL, Roberts WL. The analytic sensitivity and mutant detection capability of six hepatitis B surface antigen assays. Am J Clin Pathol. 2006;125:748-51.

34. Halima SB, Bahri O, Maamuri N, Cheikh I, Alaya NB, Sadraoui A, et al. Serological and molecular expresion of hepatitis B infecction in patients with chronic hepatitis $\mathrm{C}$ from Tunisia, North Africa. Virology J. 2010;7:229. 